\title{
Evidence for the facilitated diffusion of glucose into rabbit oviductal fluid
}

\author{
H. J. Leese and Kate S. Jeffries \\ Department of Biology, University of York, York YOI 5DD, U.K.
}

\begin{abstract}
Summary. Glucose movement into the oviductal fluid of rabbits was studied in anaesthetized animals. The oviducts were cannulated at each end, and $2 \mathrm{ml} 0.9 \% \mathrm{NaCl}$ at $37^{\circ} \mathrm{C}$ were recirculated through the lumen for $4 \mathrm{~h}$. D-Glucose appeared linearly in the fluid, reaching an average concentration of $2.6 \mathrm{mM}$. The rate of D-glucose appearance was 17 times greater than that of L-glucose, infused intravenously, suggesting that a component of the D-glucose movement operated by facilitated diffusion. The oviduct was unable to move glucose against an adverse plasma to lumen concentration gradient. We suggest that the glucose entering the oviductal fluid originates in the plasma and that the mucosal portion of the oviduct is responsible for this sugar transfer.
\end{abstract}

\section{Introduction}

The oviductal fluid provides an environment for gamete transport, fertilization and early cleavage of the egg. The detailed composition of the fluid and the hormonal influence on its constituents are known for a number of species (Hamner \& Fox, 1969; Hamner, 1973; Brackett \& Mastroianni, 1974). Oviductal fluid is a complex mixture of water, ions, carbohydrates, lipids, amino acids and proteins and may be secreted against a hydrostatic pressure. However, in contrast with other secretory or absorptive processes, such as those found in the pancreas, gall bladder, small intestine and kidney, very little is known about the mechanisms by which the oviductal fluid is formed. We have therefore examined the way in which a major constituent, glucose, is transported into the oviductal fluid of the rabbit in vivo.

\section{Materials and Methods}

The time-course of glucose appearance in rabbit oviductal fluid was followed over relatively short periods of up to $4 \mathrm{~h}$, because it was hoped that this would provide information on the initial rate of sugar transfer. The volumes of oviductal fluid formed during this period in the rabbit are only of the order of 100-200 $\mu \mathrm{l}$, and there are considerable difficulties in collecting serial, representative samples from such small volumes within the oviduct lumen. It was therefore decided to cannulate each end of the oviduct and recirculate $2 \mathrm{ml}$ perfusion medium at $37^{\circ} \mathrm{C}$ through the lumen, from the uterine to the ovarian end, removing small $(10 \mu \mathrm{l})$ samples at regular intervals from a water-jacketed reservoir incorporated into the perfusion circuit. The perfusion medium was $0.9 \% \mathrm{NaCl}$ because it is (1) a simple medium and (2) often used in analogous studies in vivo on other epithelial tissues. Streptomycin $(100 \mu \mathrm{g})$ and penicillin (200 units: both from Sigma Chemical Company Ltd, London) were added to the medium to inhibit bacterial growth. Control experiments showed that they had no effect on the rate of glucose appearance. The perfusion medium was recirculated at a rate of $50 \mu l$ $\mathrm{min}^{-1}$ with a peristaltic pump (Gilson). This flow rate ensured adequate mixing and minimized pulsation in the perfusion circuit. Doubling the flow rate had no effect on the rate of glucose appearance, but this higher flow rate was not used in case the mucosal lining of the oviduct (endosalpinx) was disrupted.

New Zealand White rabbits $(3-4 \mathrm{~kg})$ were used in all the experiments. They were anaesthetized with $35 \mathrm{mg}$ pentobarbitone sodium (Sagatal: May \& Baker Ltd, Dagenham) $\mathrm{kg}^{-1}$ and maintained under anaesthesia on a tray warmed to approximately $37^{\circ} \mathrm{C}$ throughout the experiments. Each oviduct was cannulated at its uterine and fimbriated ends with nylon tubing (i.d. $0.25 \mathrm{~mm}, 0 . \mathrm{d} . \mathbf{0 . 7 5} \mathrm{mm}$, and 
i.d. $0.75 \mathrm{~mm}$, o.d. $0.94 \mathrm{~mm}$, respectively; Portex Ltd, Hythe, Kent). The cannula at the uterine end was inserted into the oviduct through an incision in the uterus. Nylon tubing (i.d. $0.75 \mathrm{~mm}, 0 . \mathrm{d}$. $0.94 \mathrm{~mm}$ ) was used to connect the cannula at the ovarian end with the sampling reservoir, and vinyl tubing (i.d. $0.63 \mathrm{~mm}$, o.d. $1.4 \mathrm{~mm}$ ) to connect the cannula at the uterine end with the pump, and the pump with the reservoir. The femoral vein was cannulated in some experiments with nylon tubing (i.d. $0.75 \mathrm{~mm}, 0 . d .0 .94 \mathrm{~mm}$ ) to permit the withdrawal of blood and infusion of $\mathrm{L}-\left[1-{ }^{14} \mathrm{C}\right] \mathrm{glucose}$ and $\mathrm{D}-\left[2-{ }^{3} \mathrm{H}\right]$ glucose (Radiochemical Centre, Amersham) at a rate of $10 \mu \mathrm{Ci} \mathrm{ml}^{-1} \mathrm{~h}^{-1}$. Serial samples of circulating fluid and plasma were analysed for glucose by an automated method (GOD-Perid: Boehringer Mannheim GMBH) on a Technicon Autoanalyser, and when radioactive sugars were used, samples were also measured in a liquid scintillation counter (Beckman L-S230).

\section{Results}

The time-course of appearance of D-glucose in the fluid circulating through the oviduct lumen is shown in Text-fig. 1. The results from the left and right oviducts have been pooled because no difference could be detected between the two sets of values. Glucose appeared linearly for $4 \mathrm{~h}$ and by this time 5.2 $\pm 0.46 \mu \mathrm{mol}$ (S.E.M.) had accumulated. The glucose concentration in the perfusion fluid at $4 \mathrm{~h}$ was $2.6 \pm 0.23 \mathrm{mM}$ (S.E.M.). The plasma glucose concentration during the $4 \mathrm{~h}$ was $20.3 \pm 2.7 \mathrm{mM}$ (S.E.M.). When experiments were continued for longer than $4 \mathrm{~h}$, fragments of the endosalpinx were sometimes released into the circulating fluid, suggesting deterioration of the preparation; when this happened the glucose in the fluid disappeared (in about $90 \mathrm{~min}$ ) possibly due to metabolism by the underlying muscular layers.

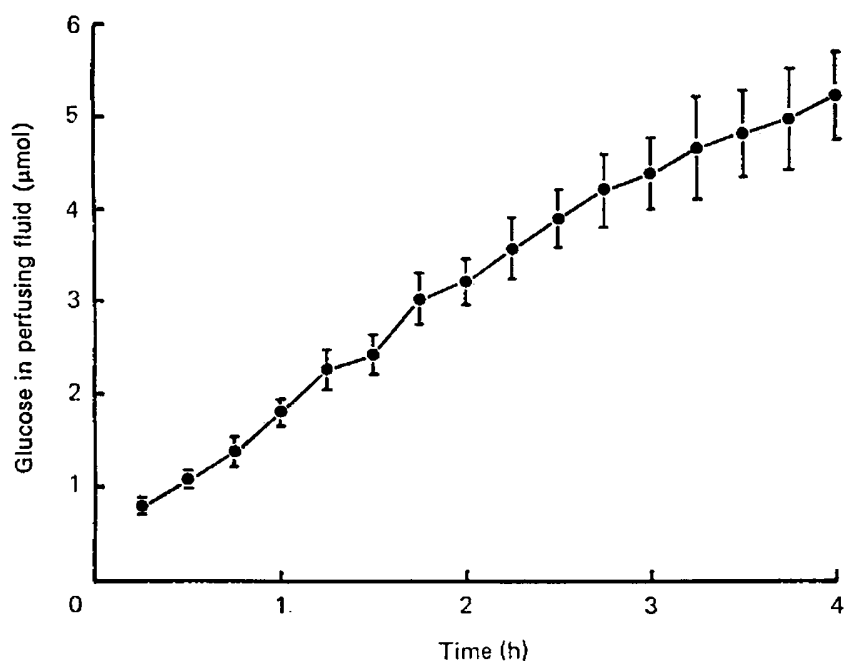

Text-fig. 1. The time-course of glucose appearance in fluid circulating through the rabbit oviduct in vivo. Values are mean \pm S.E.M. of at least 20 oviducts.

The oviducts of two animals which had been killed but whose body temperature was maintained on the warm tray were perfused immediately with fluid at $37^{\circ} \mathrm{C}$ for $4 \mathrm{~h}$; there was no glucose accumulation in the perfusing fluid.

When the perfusion fluid was loaded with glucose at a concentration of $5 \mathrm{~mm}$, i.e. at a concentration approximately double that normally achieved after $4 \mathrm{~h}$, it remained at this level throughout the subsequent 4-h incubation period. This was also the case when the fluid was loaded with glucose at a concentration approximately equal to the final plasma concentration, i.e. $20 \mathrm{~mm}$, suggesting that the oviduct cannot bring about the overall uphill transport of glucose. To check whether the glucose 
added was being absorbed by the oviduct, and then re-secreted, two experiments were carried out in

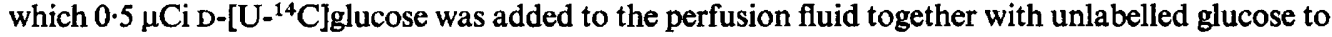
a concentration of $5 \mathrm{~mm}$. After $4 \mathrm{~h}$ the amounts of radioactivity remaining in the perfusion fluid, expressed as a percentage of that added, were 82 and $69 \%$, suggesting that relatively little exchange of the added glucose had taken place.

To decide whether the movement of glucose was by passive or facilitated diffusion, $\mathrm{L}-\left[1-{ }^{14} \mathrm{C}\right]-$ glucose and $\mathrm{D}-\left[2-{ }^{3} \mathrm{H}\right]$ glucose were infused together into the femoral vein, and their appearance in the oviductal fluid was compared. Four experiments ( 8 oviducts) were carried out, and for each the amount of unlabelled L-glucose in the infusate was varied. The results from one of these experiments are shown in Text-fig. 2 . The average plasma L-glucose in this experiment was $11.2 \mathrm{mM}$. D-Glucose and the radioactivity derived from $D-\left[2-{ }^{3} \mathrm{H}\right]$ glucose appeared in the oviductal fluid at much greater rates than did L-glucose. Text-figure 3 shows the rate of L-glucose appearance in the oviductal fluid, plotted against the average plasma $\mathrm{L}$-glucose concentration in each of the four experiments. These results suggest that within the concentration range studied L-glucose transport is a non-saturable, passive diffusion process. In contrast, in a number of other experiments (results not shown) the plasma D-glucose concentration rose spontaneously throughout the 4-h period, reaching values as high as $35 \mathrm{~mm}$, probably because of the effects of over-anaesthetization. However, in these experiments, the rate of glucose appearance in the oviductal fluid remained constant, suggesting that there was a saturable component in the overall D-glucose transfer.

It seemed possible, although unlikely, that the D-glucose appearing in the oviductal fluid could be derived solely from the washout of endogenous glucose present within the oviduct wall itself at the beginning of the experiments. To check this possibility, oviducts were removed from rabbits as

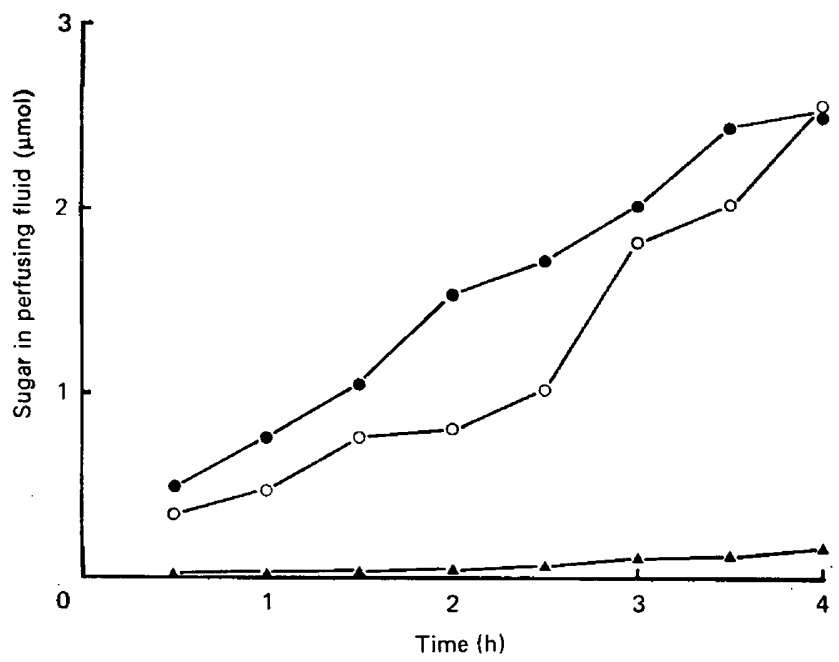

Text-fig. 2. The appearance of non-radioactive glucose (๑) and radioactivity derived from plasma $D-\left[2 \cdot{ }^{3} \mathrm{H}\right]$ glucose $(O)$ and plasma $\mathrm{L}-\left[1-{ }^{14} \mathrm{C}\right.$ glucose $(\Lambda)$ in fluid circulating through the rabbit oviduct in vivo. The values are from a single experiment. The results for the appearance of radioactivity derived from D- $\left[2-{ }^{3} \mathrm{H}\right]$ glucose at a given time were calculated according to the relationship:

total radioactivity due to ${ }^{3} \mathrm{H}$ in fluid

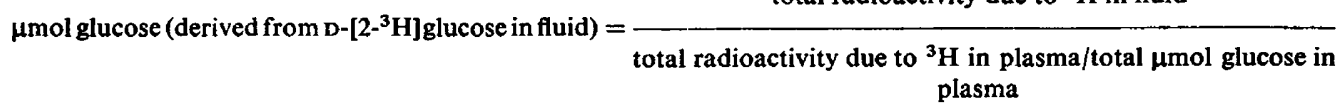

The results for the appearance of $\mathrm{L}$-glucose at a given time were calculated according to the relationship:

$$
\mu \mathrm{mol} L \text {-glucose in fluid }=\frac{\text { total radioactivity due to }{ }^{14} \mathrm{C} \text { in fluid }}{\text { specific activity of } \mathrm{L}-\left[1-{ }^{14} \mathrm{C}\right. \text { glucose }} .
$$




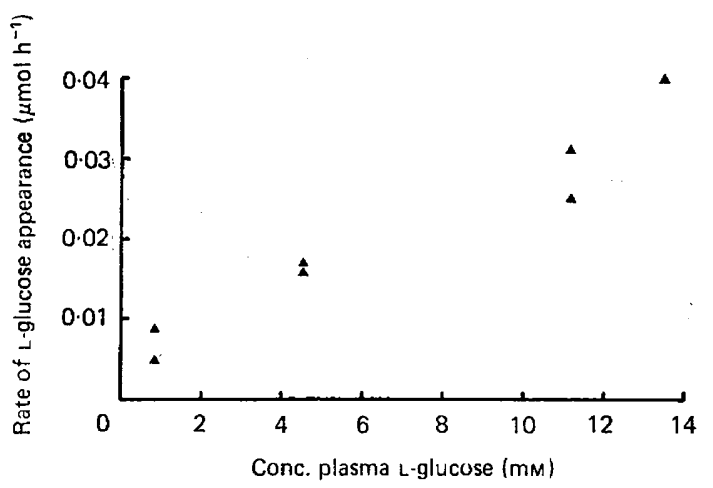

Text-fig. 3. The rates of appearance of plasma $L-\left[1-{ }^{14} \mathrm{C}\right]$ glucose in fluid circulating through the rabbit oviduct in vivo as a function of plasma $\mathrm{L}-\left[1-{ }^{14} \mathrm{C}\right]$ glucose concentration. Each point represents the result from a single oviduct.

rapidly as possible and their glucose content measured. The average value was $2 \mu \mathrm{mol}$ per $\mathrm{g}$ fresh tissue and if all of this glucose were released into the $2 \mathrm{ml}$ of perfusion fluid, it could account for, at most, $10 \%$ of the glucose appearance at $4 \mathrm{~h}$.

\section{Discussion}

The present results provide evidence that glucose enters the rabbit oviductal fluid not solely by passive diffusion, but that a component of the glucose movement is mediated in some way. We have also shown that the oviduct cannot bring about the overall uphill transport of glucose, which is not surprising, since there is normally a downhill gradient of glucose from the plasma to the oviduct lumen. We therefore suggest that there is a component of the transfer of glucose into the oviductal fluid which operates by facilitated diffusion. Direct evidence in favour of this proposition comes from the experiments in which the rates of $D$ - and $L$-glucose appearance were compared (Text-fig. 2 ) and in which it was found that D-glucose moved at approximately 17 times the rate of L-glucose. LGlucose is not metabolized by the rabbit and is probably transferred by passive diffusion (see Textfig. 3). The slower rate of appearance of radioactivity derived from $\mathrm{D}-\left[2-{ }^{3} \mathrm{H}\right] \mathrm{glucose}$ in the fluid than that of unlabelled glucose is probably because some of the radioactivity in the oviductal fluid and the plasma was due to glucose metabolites, such as lactate, which were not measured in the experiments. The conversion of total radioactivity into $\mu \mathrm{mol}$ glucose (Text-fig. 2) assumed that all the counts in the plasma were due to unchanged $\mathrm{D}-\left[2-{ }^{3} \mathrm{H}\right]$ glucose, and this led to an overestimate of plasma glucose specific activity, which in turn would give an underestimate of the amount of radioactivity derived from $\mathrm{D}-\left[2-{ }^{3} \mathrm{H}\right]$ glucose in the oviductal fluid.

The results in Text-fig. 2, the experiments on dead animals, and the calculation derived from the glucose content of the oviduct, strongly suggest that the origin of the glucose appearing in the oviductal fluid is the plasma. The lack of glucose secretion after disruption of the endosalpinx suggests that it is the mucosal portion of the oviduct which is responsible for the glucose movement. The retention for $4 \mathrm{~h}$ of unlabelled glucose and of about $75 \%$ of the radioactivity derived from $\mathrm{D}-\left[\mathrm{U}-{ }^{14} \mathrm{C}\right]-$ glucose added to the oviductal fluid at zero time indicates that the glucose flux from oviduct lumen to plasma was small under the experimental conditions. However, it is difficult to understand why glucose should not have continued to appear in the oviduct after loading of the perfusion fluid with $5 \mathrm{~mm}$ glucose, because an approximately fourfold gradient of glucose from plasma to oviduct lumen still existed.

The 4-h concentrations and absolute amounts of glucose appearing in the medium perfusing the oviducts were about four times greater than those reported for rabbit oviductal fluid collected over 24 h (Holmdahl \& Mastroianni, 1965; Iritani, Nishikawa, Gomes \& VanDemark, 1971). One explana- 
tion for this discrepancy is that when the oviduct is perfused, as in the present study, the glucose is rapidly cleared from the sites of secretion, preventing the build up of high local concentrations of glucose, and unstirred layers of fluid which might inhibit further glucose output.

Oviductal fluid is thought to be produced by selective transudation of blood constituents, and by the secretion of specific constituents by the endosalpinx (Hamner \& Fox, 1969; Hamner, 1973; Brackett \& Mastroianni, 1974). We have provided evidence for the selective downhill movement of glucose from plasma to oviduct lumen, and are at present investigating the details of this transport process. Glucose has been shown to be a potential substrate for spermatozoa, and cleavage stage embryos, and its presence in the oviductal fluid is therefore likely to be of importance in the early events of reproduction (Brackett \& Mastroianni, 1974).

We are grateful to Dr P. Ingham for some extremely useful discussions, to Dr F. Karim for demonstrating the technique of femoral cannulation, and to the Medical Research Council for the grant which made this research possible.

\section{References}

BracketT, B.G. \& MastroianNi, L., Jr (1974) Composition of oviducal fluid. In The Oviduct and its Functions, pp. 133-150. Eds A. D. Johnson \& C. W. Foley. Academic Press, New York.

HAMNer, C.E. (1973) Oviducal fluid-composition and physiology. Handbook of Physiology, Section 7, Vol. II, Part 2, pp. 141-170. Eds R. O. Greep \& E. B. Astwood. American Physiological Society, Washington, D.C.

HaMner, C.E. \& FoX, S.B. (1969) Biochemistry of oviductal secretions. In The Mammalian Oviduct, pp. 333-355. Eds E. S. E. Hafez \& R. J. Blandau, University of Chicago Press.

Holmdahl, R.H. \& MASTROIANNI, L., Jr (1965) Continuous collection of rabbit oviduct secretions at low temperature. Fert. Steril. 16, 587.

Iritani, A., Nishikawa, Y., Gomes, W.R. \& VaNDEMARK, N.L. (1971) Secretion rates and chemical composition of oviduct and uterine fluids in rabbits. J. Anim. Sci. 33, 829-835.

Received 9 February 1977 